\title{
Educating Knowledgeable and Skilled Researchers in Doctoral Programs in Schools of Education: A New Model
}

\author{
Nancy L. Leech \\ University of Colorado Denver, Denver, CO, USA
}

Nancy.Leech@ucdenver.edu

\begin{abstract}
To better understand how skilled and knowledgeable researchers develop in schools of education, the process of becoming a successful researcher needs to be explored. The purpose of the paper is to present three theories/studies including scientific and technical human capital, Levine's study of schools of education, and Lovitts' model of the factors that lead doctoral students to be successful researchers; to review the extant literature; and to delineate a new model to assist faculty in thinking about educating skilled and knowledgeable researchers. It is hoped that this new model will advance our understanding about what it takes to educate skilled and knowledgeable researchers in schools of education.
\end{abstract}

Keywords: teaching research; doctoral education, successful researchers, skilled researchers, graduate teaching, scientific and technical human capital, Levine's study of schools of education, Lovitts' model of the factors that lead doctoral students to be successful researchers

\section{Introduction}

As evidenced by the numerous advertisements in the Chronicle of Higher Education and a multitude of list-serves, organizations across the United States are searching for graduates who can do the work of knowledgeable and skilled researchers. According to Walker, Golde, Jones, Conklin Bueschel, and Hutchings (2008):

Approximately one-half of those who receive doctorates this year will join the ranks of college and university faculty who educate today's undergraduates, some of whom will become teachers themselves, in the United States and beyond, shaping the futures of our children and grandchildren. And some will prepare new PhD's [sic], so the effects of doctoral education ripple out across nations and generations. (p. 1)

When a student graduates from a Ph.D. program, having the letters "Ph.D." after his or her name purports one definitive ability has been acquired: to conduct original research and scholarship in

Material published as part of this publication, either on-line or in print, is copyrighted by the Informing Science Institute. Permission to make digital or paper copy of part or all of these works for personal or classroom use is granted without fee provided that the copies are not made or distributed for profit or commercial advantage AND that copies 1) bear this notice in full and 2) give the full citation on the first page. It is permissible to abstract these works so long as credit is given. To copy in all other cases or to republish or to post on a server or to redistribute to lists requires specific permission and payment of a fee. Contact Publisher@InformingScience.org to request redistribution permission. order to contribute to existing knowledge (Association of American Universities, 1998). Yet, "not much is known about how to foster [the] capacity for excellence in research and scholarship" (Walker, et al., 2008, p. 151). The lack of knowledge in how to educate researchers is further apparent in published educational research. Feuer, Towne, and Shavelson (2002) suggested "the quality of educational research is 
wanting" (p. 4). There has been ample research conducted regarding doctoral student attrition (Bowen \& Rudenstine, 1992; Lovitts, 2001; National Research Council, 1996; Nerad \& Cerny, 1991), yet, there has been little research to investigate how to educate and graduate skilled and knowledgeable researchers.

It is logical to assume that top schools (e.g., Stanford, Vanderbilt, etc.) will be successful at educating researchers. These schools typically have the top applicants who are good students, with a multitude of opportunities including resources to support research. Many other schools have students who are not able to relocate to another state to attend school, are not the top applicants in the nation, and, many times, are part-time students. Not all schools attract top students or have extensive resources; yet, there must be ways to produce successful researchers, regardless of the program attended. Thus, the purpose of the present paper is to present three theories/studies, review the extant literature, and delineate a new model to assist faculty in thinking about educating skilled and knowledgeable researchers.

\section{Educating Skilled and Knowledgeable Researchers: Three Extant Theoretical Frameworks}

To better understand how to educate skilled and knowledgeable researchers, three theories/studies are applicable: the theory of scientific and technical (S\&T) human capital (Bozeman, Dietz, \& Gaughan, 2001), Levine's (2007) study of schools of education, and Lovitts' (2005) model of the factors that lead doctoral students to be successful researchers. Each of these theories/studies is briefly described.

\section{Bozeman, Dietz, \& Gaughan (2001) Theory of S\&T Human Capital}

S\&T human capital comprises human capital and social/research project capital (Bozeman, Dietz, \& Gaughan, 2001). According to Bozeman et al., human capital consists of a person's cognitive skills, knowledge, and craft skills. On the other hand, social capital, according to Bourdieu and Wacquant (1992), is "the sum of resources, actual or virtual, that accrue to an individual or group by virtue of possessing a durable network of more or less institutionalized relationships of mutual acquaintance and recognition" (p. 119). In this adapted model, social capital is measured by research projects. Figure 1 depicts an adaption of the S\&T human capital model.

This revised version of the S\&T human capital model has four main features. First, the amount of cognitive skills is measured by the cross marks; the lower the cross mark is on the line, the less skills and knowledge. Next is the amount of knowledge, which is also assessed by where the cross marks are, with lower cross marks indicating less knowledge. Above these measurements is social capital, as measured by research projects which the researcher is involved with. The squares represent quantitative research projects, the circles represent qualitative research projects, and the triangles represent mixed methods research projects. The lines between the projects indicate the level of participation of the researcher, from low participation (e.g., being third or fourth author) to high participation (e.g., being first or second author).

This adapted model depicts in the first section, on the left of the model, a novice researcher. The novice researcher is assessed on his or her cognitive skills and knowledge. It is shown to be low, as indicated by the cross marks being low and thus measuring a low amount of cognitive skills and knowledge in relation to research ability. The novice researcher also has very little social capital, or research projects, in this adapted model, which is indicated by having only three projects (the two squares and circle). 

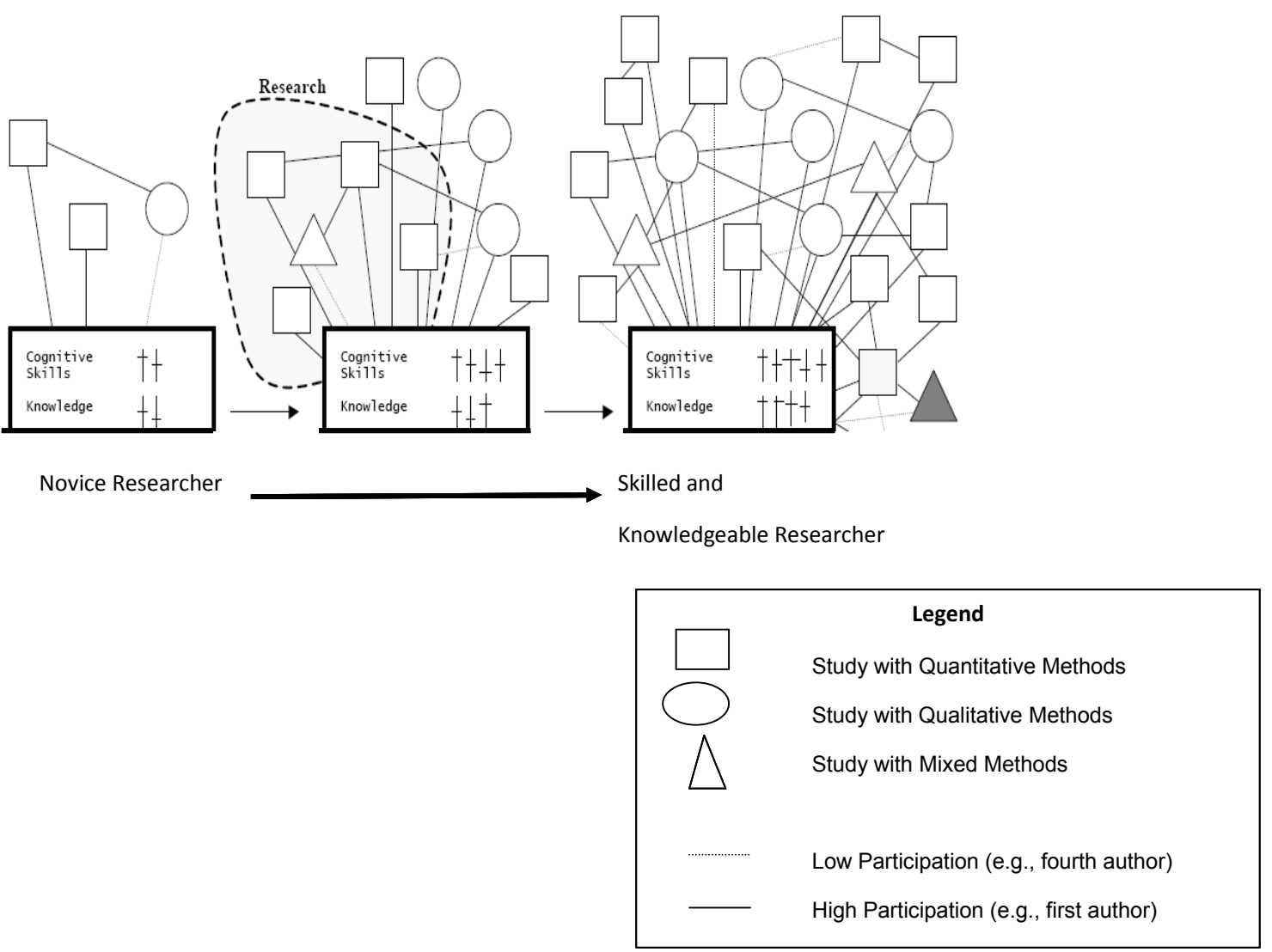

Figure 1. The S\&T Human Capital model (Adapted from Bozeman, Dietz, \& Gaughan, 2001).

The middle section depicts a researcher with average cognitive skills and knowledge (i.e., the cross marks are mostly in the middle of the line) and a few research projects (i.e., there are only ten research projects and not many linkages between each). Section three, on the far right of the figure, depicts a skilled and knowledgeable researcher with high levels of cognitive skills and knowledge; as seen, most of the cross marks are at the top of the lines. This researcher also has a significant number of social contacts/research projects. Furthermore, the skilled and knowledgeable researcher has high participation, being first or second author much of the time, indicated by the multiple solid lines connecting the projects. The S\&T human capital theory fits well with the educating skilled and knowledgeable researchers; instead of focusing on immediate outcomes, this theory focuses on scientists' career trajectories and ability to continue to contribute to the field as well as increase their own knowledge.

\section{Levine's (2007) Study of Schools of Education}

Levine (2007) investigated schools of education across the country utilizing a nine-point template to better understand what factors are associated with schools that produce successful researchers. One definition of success that is presented by Levine is "the preparation of grant proposals and the writing and presentation of research papers" (p. 25). The nine-point template focuses on the program (i.e., purpose, admissions, graduation and degree standards, finances), the faculty (i.e., productivity, expert teachers, and research quality), and the curriculum (i.e., how well it matches the purpose and goals of the program, how often the students have other experiences outside of the classroom, as well as assessment). 
Utilizing his nine-point template, Levine examined the ability of faculty in schools of education across the country to graduate skilled researchers who have impact on policy, practice, and increasing understanding of human development and learning. The main research question was "Do current preparation programs have the capacity to equip researchers with the skills and knowledge necessary to carry out research that will strengthen education policy, improve practice or advance our understanding of how humans develop and learn?" (p. 15). The nine areas investigated in each program included the following: (1) purpose, (2) curriculum coherence, (3) curriculum balance, (4) faculty, (5) admissions, (6) graduation and degree standards, (7) research, (8) finances, and (9) assessment.

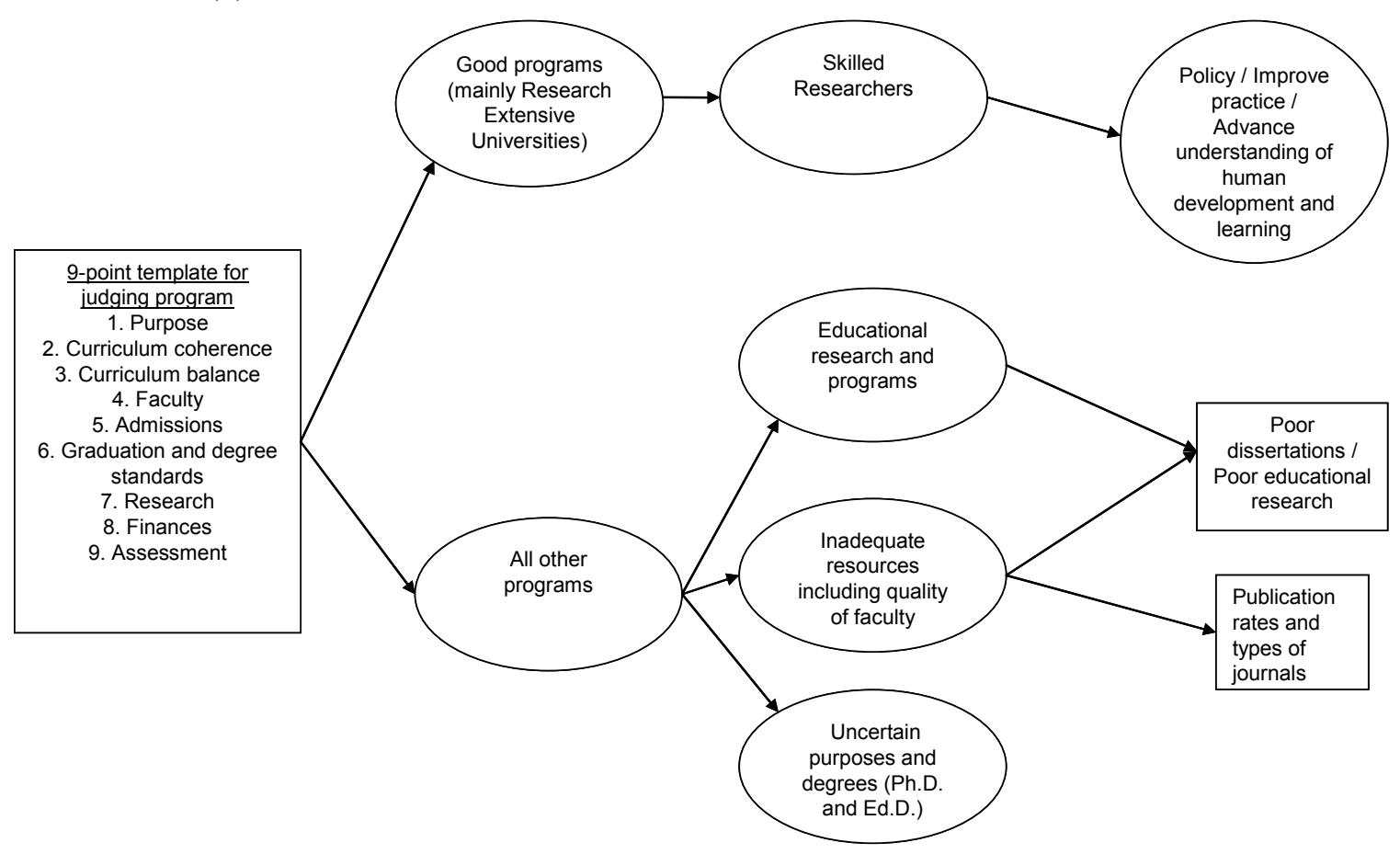

Figure 2. Graphical depiction of Levine (2007).

Figure 2 presents a graphical depiction of Levine's thesis. As can be seen in the figure, based on Levine's (2007) nine points, schools of education are either exemplary or inadequate. According to Levine, an:

exemplary program is one that substantially meets all nine criteria. A strong program is one that substantially satisfies most of the criteria. An inadequate program is defined as one that fails to achieve most of the criteria or has a fatal flaw, such as having faculty who do not publish. (p. 16)

The findings from Levine's (2007) study indicate most programs across the nation do not equip researchers with necessary research skills and abilities. Based on Levine's findings, these weak programs tend to fail in three areas: (a) educational programs and published research lack agreed upon, rigorous standards, (b) inadequate resources, including quality faculty who are productive researchers, faculty who are able and available to mentor doctoral students with dissertations, and resources to encourage full-time doctoral students, and (c) uncertain purposes and degrees, including the mixing of Ph.D. and Ed.D. degrees with varying expectations and requirements. Recommendations from Levine's study include to "establish effective means of quality control within the education research community" (p. 77) and to investigate doctoral programs to the extent they 
"employ rigorous and appropriate standards - growing out of the National Research Council report” (p. 77).

\section{Lovitts (2005)}

Another theory that is beneficial in understanding how to develop skilled and knowledgeable researchers is from Lovitts (2005). According to Lovitts, there are many factors that contribute to producing skilled and knowledgeable researchers. Lovitts developed a theoretical model to increase understanding of the factors that lead doctoral students to "produce outstanding research and scholarship" (p. 139). Figure 3 provides the full model.

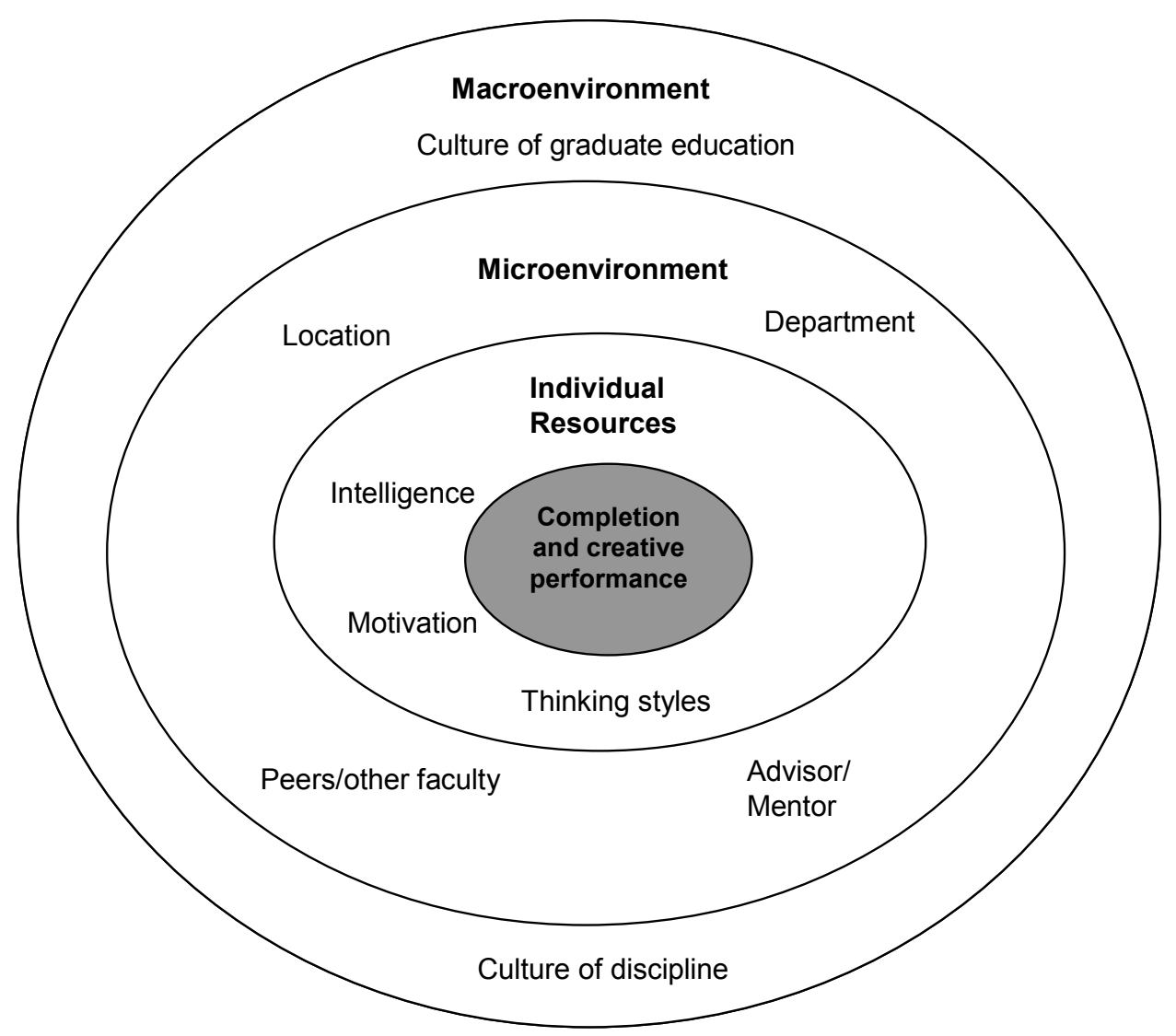

Figure 3. Model for understanding doctoral student success (Lovitts, 2005).

At the core of the model is doctoral student completion and creative performance (i.e., the dissertation). The model consists of three main layers. First are individual resources. The five individual resources or personal characteristics impact student completion and creative performance: (a) intelligence, (b) motivation, (c) knowledge, (d) personality, and (e) thinking styles. Microenvironment, the second layer, includes the location, peers/other faculty, the department, and the advisor. The third layer is designated the macroenvironment. It includes the culture of graduate education and the culture of the discipline. According to Lovitts (2005) these three layers, the individual resources, the microenvironment, and the macroenvironment, interact. If any facet of the layers is deficient, the probability of a student completing the program and producing a quality dissertation decreases. 


\section{Comparison of the Three Theories: Understanding the Similarities and Differences}

The three models, Bozeman, Dietz, \& Gaughan (2001), Levine (2007), and Lovitts (2005) each present interesting aspects in relation to developing skilled and knowledgeable researchers. Figure 4 presents the aspects of the models and where they are similar and different to one another. The first column depicts the components of Lovitts (2005), including the macroenvironment (i.e., the culture of graduate education and the culture of the discipline), the microenvironment (i.e., advisors/mentor and peers/other faculty), and the individual resources (i.e., motivation, personality, thinking styles, knowledge, and intelligence). The second column presents the nine aspects of programs identified by Levine (2007): purpose or program, finances, faulty, research, curriculum coherence, curriculum balance, admissions, graduation and degree standards, and assessment. Finally, the third column portrays an adaption of Bozeman, Dietz, and Gaughan's (2001) theory of scientific and human capital, including projects working on, level of participation in the projects, cognitive skills of the researcher, and knowledge of the researcher. The arrows connect similar aspects of each of the theories. Thus, under Lovitts' microenviroment, the concepts of advisor/mentor and peers/other faculty fit with faculty from Levine's theory. Likewise, under individual resources, motivation links to level of participation under Bozeman, Dietz, and Gaughan. There are a total of three linkages between Lovitts and Levine, all under the microenvironment. Between Levine and Bozeman, Dietz, and Gaughan there are at total of five linkages, with all but one focusing on projects in Bozeman, Dietz, and Gaughan. Finally, between Lovitts and Bozeman, Dietz, and Gaughan there are a total of seven linkages, all from individual resources to level of participation, cognitive skills, and knowledge.

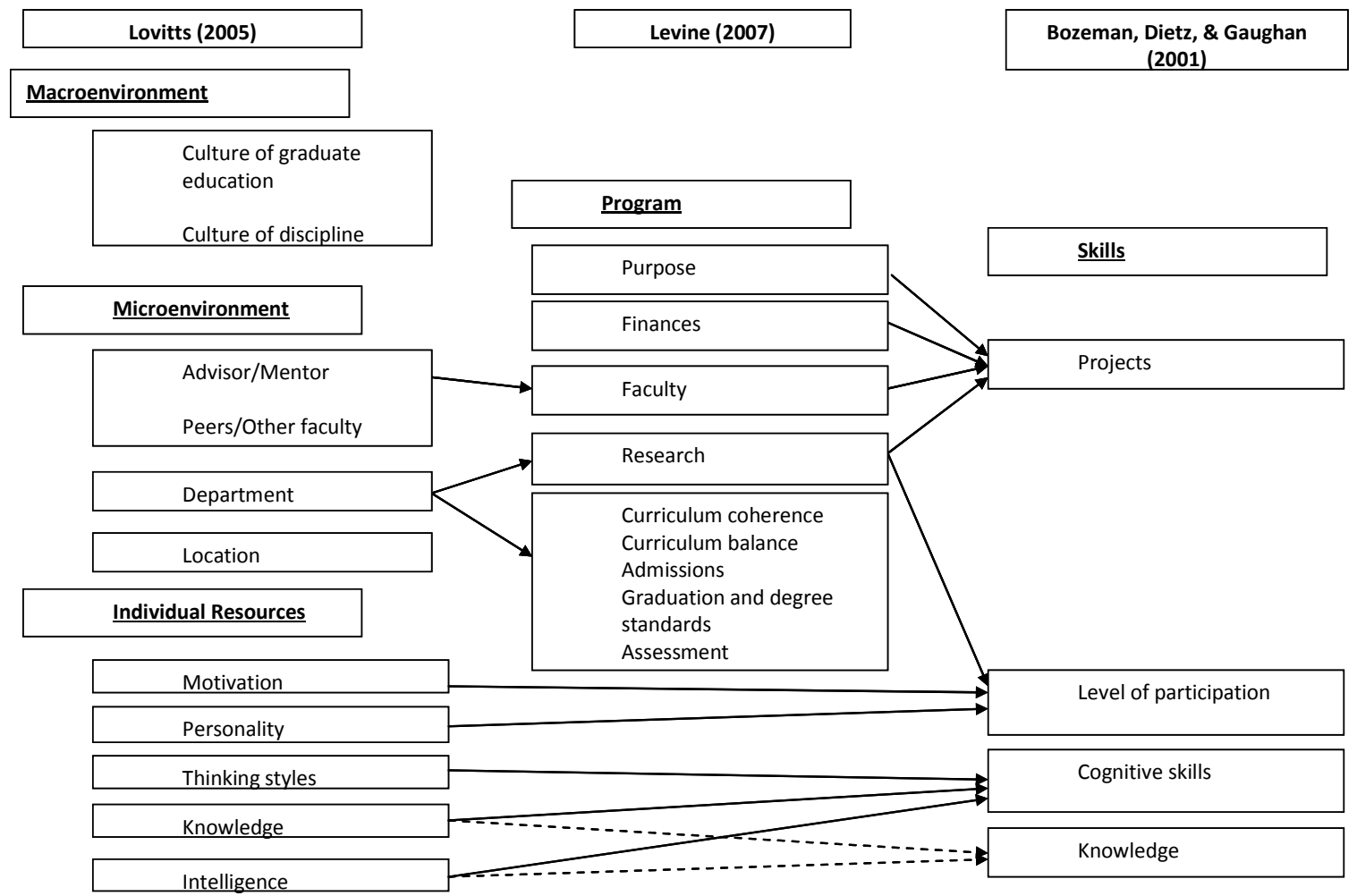

Figure 4. Comparison of the three theories.

Figure 4 also presents aspects that are not linked between the theories. All boxes without arrows stemming from them or leading to them are not linked to other theories. For Lovitts (2005) these include culture of graduate education, culture of the discipline, and location. For both Levine 
(2007) and Bozeman, Dietz, and Gaughan (2001), all of the boxes are linked to some other aspect in the other theories. Therefore, the only unique concepts (i.e., those that do not cross more than one theory) include the three concepts from Lovitts (i.e., culture of graduate education, culture of the discipline, and location).

\section{Integration of the Three Theories: A New Framework for Understanding Skilled and Knowledgeable Researchers}

The three theories/studies by Bozeman, Dietz, and Gaughan (2001), Levine (2007), and Lovitts (2005) present different components for understanding how to develop skilled and knowledgeable researchers. In what follows, the extant literature regarding each of these components, as well as other issues regarding developing skilled and knowledgeable researchers, is presented. This is organized with Lovitts' (2005) headings, in order to help the reader map this information onto Figure 4.

\section{Macroenvironment: Culture of Graduate Education and the Culture of the Discipline}

There is little research on the culture of graduate education and the culture of the discipline. These two concepts are seen as being similar across all institutions; thus, all students in the same discipline should experience a similar culture (Golde, 2005). As Golde states:

departmental practices and cultural assumptions about doctoral education are shaped by disciplinary norms and practices (including the job market in the discipline) and by the nature of research and scholarship in the discipline. (p. 671)

Yet, we do not know if the culture of graduate education and the culture of the discipline are similar across schools. Without evidence, we cannot be sure what type of culture(s) students are presented with.

\section{Microenvironment: Faculty: Advisor/Mentoring}

There has been extensive research done on effective faculty/student mentoring relationships in academia (L. E. Anderson \& Carta-Falsa, 2002; Luna \& Cullen, 1998; Paglis, Green, \& Bauer, 2006; Rose, 2003; Samuel \& Kohun, 2010). Mentoring has been defined by E. M. Anderson and Shannon (1988) as:

a nurturing process in which a more skilled or more experienced person, serving as a role model, teaches, sponsors, encourages, counsels and befriends a less skilled or less experienced person for the purpose of promoting the latter's professional and /or personal development. (p. 40)

The mentoring relationship is important; as stated by Bargar and Mayo-Chamberlain (1983), "the advisor is correctly seen as the 'significant other' for the student's journey..." (p. 420). This relationship appears to be beneficial for both the student and faculty member; as McAlpine and Norton (2006) assert, a student can frequently be the supervisor's closest colleague.

From the students' perspective, mentoring is seen as being extremely important and beneficial (Luna \& Cullen, 1998). In a study by Luna and Cullen (1998), 83\% of the doctoral students reported they believed mentoring was important; in fact, all but four of the 109 respondents reported having a mentor. Paglis, Green, and Bauer (2006) found having a mentor through the first two years of a doctoral program predicted the students' research productivity four years later. Additionally, Paglis, Green, and Bauer identified the relationship between mentoring and research 
self-efficacy of the student. Thus, having a mentor can positively affect a student's skill and knowledge of research.

Unfortunately, many faculty are not taught how to mentor (Golde \& Dore, 2001). Mentoring can be viewed as a different form of teaching (Saroyan et al., 2004), yet, some faculty do not understand this existing relationship between teaching and mentoring. This misunderstanding leads to faculty not mentoring students well, or not mentoring at all. If students are to learn how to be successful researchers, having a mentor who can and will guide them through the process is paramount (Levine, 2007).

\section{Microenvironment: Peers and Other Faculty}

There is little research on peers and faculty in relation to doctoral students (Giles \& Endsley, 1988). For this discussion, peers include other doctoral students, whereas faculty include the instructors in the doctoral program. Kram and Isabella (1985) examined the role of peers as an alternative to mentors. They found that peers provide counseling, support, and technical expertise, throughout the students' program. Another study found peers were rated higher than advisors on communication and affective bond (Endsley \& Giles, 1988). Thus, having positive peer interactions can increase the likelihood of a student completing the doctoral program (Pontius \& Harper, 2006).

\section{Microenvironment: Department}

The quality of the department can significantly impact the level of skill graduates obtain. Golde and Dore (2001) found that most doctoral programs do not meet students' needs or expectations. Furthermore, and most disturbing, they found that students felt their doctoral program did not prepare them for future jobs.

\section{Microenvironment: Curriculum}

Curriculum is more than the materials, textbooks, etc.; curriculum is the experience the student undergoes (Posner, 1992). Posner stated curriculum as being:

the content or objectives for which schools hold students accountable. Others claim that a curriculum is the set of instructional strategies teachers plan to use...Others argue that plans, whether for ends or means, are insignificant when compared with actual learnings and actual instructional methods. (p. 4)

Traditionally, curriculum has included the following: (a) scope and sequence of material, (b) syllabus, (c) content outline, (d) textbooks, (e) course of study, and (f) planned experiences (Posner, 1992). Pinar, Reynolds, Slattery, and Taubman (1995) take the concept of curriculum further by suggesting:

Curriculum ceases to be a thing, and it is more than a process. It becomes a verb, an action, a social practice, a private meaning, and a public hope. Curriculum is not just the site of our labor, it becomes the product of our labor, changing as we are changed by it. (p. 848)

Thus, curriculum is "an opportunity...we realize that curriculum changes as we engage it, reflect on it, and act in response to it, toward the realization of our private-and-public ideals and dreams" (Pinar, 2004, p. 187). Furthermore, curriculum extends beyond the courses, textbooks, etc. to include interactions and experiences.

Educators have been questioning what defines "best practice" for methods curriculum in education doctoral programs (Lagemann \& Shulman, 1999; Page, 2001). Many are interested in knowing more about methods course requirements in order to know if the courses offered are the best 
courses to help students to become successful researchers. In 2001, an entire issue of the journal Educational Researcher was devoted to this topic, which can be illustrated through the following four questions posed by Page in the same issue:

Should doctoral programs require preparation in research methods and if so, why? Should all students, regardless of their career aspirations or talents, gain competence in research methodology, and in one or several? How should research methodologies be taught to effect particular habits of mind - in reading courses focused on research classics: realworld research experiences? small research groups? individual apprenticeships? And how much of a doctoral program should be devoted to methodological preparation, as opposed to foundational or empirical literatures on key topics? (p. 19)

Surprisingly, since the publication of this article, there has been little empirical research to investigate these questions, even though the faculty in many doctoral programs in education are likely very interested in these issues (Page, 2001).

Additionally, the educational community has not agreed upon what types of research and analyses courses are important for doctoral students. A survey of doctoral programs in education (Leech \& Goodwin, 2008) found the mean number of required methods courses for the 100 programs included in the study was 4.48 , with a range from zero to 11 (median $=4.48$, mode $=4$ ). This is an extremely large range. Most programs (63\%) required statistics, $23 \%$ required a measurement course, $62 \%$ required a qualitative research methods course, and $62 \%$ required a quantitative research methods course. If the hope is to produce skilled and knowledgeable researchers, then research needs to be conducted investigating what courses are necessary to achieve this goal.

\section{Microenvironment: Instruction}

To do rigorous research, one must be able to write research questions and choose the appropriate research paradigm and design with which to carry out the study (Onwuegbuzie \& Leech, 2005a). The fourth wave of research, that of mixed research (Johnson \& Onwuegbuzie, 2004), can help students to fully understand how to conduct qualitative, quantitative, and mixed research studies. One reason students may struggle with research is their fear of statistics. Most education programs require at least one quantitative methods course (Leech \& Goodwin, 2008; Mundfrom, Shaw, Thomas, Young, \& Moore, 2003). Unfortunately, many students tend to have negative experiences with these courses, and these courses are reported to be the most difficult (Murtonen \& Lehtinen, 2003). High levels of statistics anxiety is common for many of these students (Onwuegbuzie \& Wilson, 2003), which is defined by Zeidner (1990) as "a performance characterized by extensive worry, intrusive thoughts, mental disorganization, tension, and physiological arousal ...when exposed to statistics content" (p. 319). Statistics anxiety can seriously impact students' perceptions of research. Researchers have found statistics anxiety to be the best predictor of achievement in research methodology courses (Onwuegbuzie, Slate, Paterson, Watson, \& Schwartz, 2000) and statistics courses (Fitzgerald, Jurs, \& Hudson, 1996). Additionally, an overall negative relationship has been found between statistics anxiety and course performance (Elmore, Lewis, \& Bay, 1993; Lalonde \& Gardner, 1993; Onwuegbuzie \& Seaman, 1995; Zanakis \& Valenza, 1997; Zeidner, 1991). Unfortunately, statistics anxiety can be all encompassing for a student; it primarily affects students' ability to fully understand research articles, as well as to analyze and to interpret statistical data (Onwuegbuzie, 1997).

Some students struggle so intensely with statistics and quantitative methods that they turn to qualitative research as a method for their dissertations, many times not taking the quantitative courses that would help them become successful with their research. This mono-method outlook forces these students to answer research questions using only qualitative methods, thus, becoming "uniresearchers" (Onwuegbuzie, 2000). These researchers are unable to conduct "bi-lingual research" 
(Tashakkori \& Teddlie, 2003, p. 64). This problem is pervasive and has large consequences. As Onwuegbuzie and Leech (2005b) state, "uni-research is a threat to the advancement of the social and behavioral sciences. Indeed, as long as we stay polarized in research, how can we expect stakeholders who rely on our research findings to take our work seriously?" (p. 268).

\section{Microenvironment: Assessment}

Most programs typically accept students based on test scores (i.e., Graduate Record Exam [GRE]) and grade point average in undergraduate or master's level courses. These indicators are assessments of a student's ability to be a "good course-taker" (Lovitts, 2005, p. 138). Yet, numerous studies have found that as many as $40-50 \%$ of doctoral students leave without completing the required coursework (Bowen \& Rudenstine, 1992; Lovitts, 2001; National Research Council, 1996; Nerad \& Cerny, 1991). Thus, it appears that many students cannot get through the hurdle of doctoral coursework. In addition, the qualifying exam is another possible barrier. Because there is very little research on qualifying exams, much more research needs to be conducted to understand their importance.

Another type of assessment for doctoral students is the dissertation. Dissertations are viewed as a hurdle to graduation by many doctoral candidates. Utilizing Sternberg and Lubart's (1995) list, Lovitts (2005) described six factors needed to complete a creative dissertation, including intelligence, knowledge, thinking styles, personality, motivation, and environmental context. Furthermore, Jiranek (2010) found for students in Australia, those who complete their dissertations in a timely manner "are likely to be in the School of Chemistry and Physics, be male, international students who hold a scholarship" (p. 11). Jiranek suggests further investigation into the following:

student attributes (i.e. academic record, English language proficiency, communication skills, disabilities, number of dependents, financial situation, support from friends and family, etc), research infrastructure (i.e. extent to which the research/study facilities fulfill the needs of the project, project funding, access to key equipment or facilities, travel support or funding to access specialist facilities, library and computing facilities, etc) and supervisory arrangements (i.e. nature, frequency and effectiveness of supervisory meetings, nature of student induction program, supervisor experience, involvement of student in presentations/publications, introduction to and interaction with peers, etc). (p. 11)

Collecting data on these variables would assist faculty in better understanding what helps students complete their dissertations.

\section{Microenvironment: Standards}

A possible reason for the scarcity of skilled and knowledgeable researchers is the lack of standards available for educational research. In order to have quality control, an agreed upon standard needs to be identified; what is "good" when it comes to educational research and researchers? Recently, good educational research was defined by Hostetler (2005): "education researchers must be able to articulate some sound connection between their work and a robust and justifiable conception of human well-being" (p. 16). Hostetler goes on to say:

we have a particular obligation and opportunity to take a leading role in seeing that the research that is done is truly good research. As we do our work, we need to think beyond questions of how we will study students or analyze school policies: We need to think about how we can make life better for people. We need to think beyond our taken-forgranted ideas of well-being and what is good and make those ideas the objects of serious, communal inquiry. Serving people's well-being is a great challenge, but it is also our greatest calling. (p. 21) 
This is a move in the right direction, but it is an amorphous definition. To improve educational research, specific guidelines that outline what is "good" in order to assist novice researchers in knowing what the expectations are need to be found. Additionally, specific guidelines would assist professors in educating students to become knowledgeable and skilled researchers.

In 2002, the National Research Council (NRC) identified six aspects of research that are essential for all scientific research. These included (a) significant questions that can be empirically investigated, (b) linking research questions to relevant theory, (c) directly investigating the question, (d) a chain of reasoning that is clear and coherent, (e) replicating findings and generalizing findings, and (f) disclosing data and methods to promote critiques and open discussion. This attempt at outlining important aspects of research was a beginning for the educational community in delineating the fundamental characteristics of research. Interestingly, little research has been conducted utilizing these guidelines.

Another response to the quandary regarding guidelines for research was introduced in 2006. The American Educational Research Association (2006) created the Standards for Reporting on Empirical Social Science Research in AERA Publications to assist researchers in reporting research. The authors of this publication state, "The aim of specifying reporting standards...is to assist researchers in the preparation of manuscripts that report such work" (p. 1). These standards are only a beginning; if researchers are held to these expectations, then students need to be educated to meet these standards. Yet, there are no guidelines for how to educate students in order to have them develop into skilled researchers.

Whatever term used, whether standards, guidelines, or rubrics, the focus should be on producing skilled and knowledgeable researchers. As Levine (2007) so aptly states, "The simple fact is that if strong and clear standards are not set for education research by the education community, they will surely be set by government" (p. 77). Because it is not clear what the goal of "good research" is, it is difficult, if not impossible to know how to educate students to become highly productive, skilled, and knowledgeable researchers.

\section{Microenvironment: Location}

The location of the school is an important aspect for many doctoral students (Pierce \& Smith, 1994; Tyler \& Smith, 1999). Tyler, Smith, and Pion (2003), in a study of special education doctoral students, found that most (72\%) applied to only one doctoral program and that $79 \%$ had applied to a program within 100 miles of where they lived. Of those who applied to two or more programs, $46 \%$ did not relocate. The results indicate, "The ability or desire to relocate appears to be an important factor in the selection of a doctoral program" (p. 197). Student who were younger, with no dependents, and planning on attending school full-time were more likely to relocate. Tyler, Smith, and Pion conclude, "Today, it appears fewer doctoral students come from a national pool; instead many attend doctoral programs close to their work and residence" (p. 202). In fact, Jablonski (2001) found one of the major motivating reasons for students to begin a doctoral program is the proximity of the school. Therefore, faculty need to focus their recruiting efforts on potential doctoral students who live nearby, perhaps who are currently working in neighboring school districts or who are completing master's degrees at the university.

\section{Individual Resources: Intelligence}

One identifying factor of people who are in doctoral programs is that they are intelligent (Lovitts, 2005). There are many types of intelligence (Gardner, 1983; Sternberg, 1997). Beyond the studies utilizing the GRE and the Miller Analogies Test (MAT), which are thought to measure intelligence (Mupinga \& Mupinga, 2005), there is very little research on intelligence and doctoral stu- 
dents. Not being able to rely on these indicators puts faculty in a difficult position. As Pontius and Harper (2006) state,

Contrary to popular belief that academically ill-prepared students are weeded out, no correlation has been found between attrition and Graduate Record Exam scores, undergraduate grade point averages, and previous institutions from which bachelor's degrees were earned (Bair and Haworth, 1999; Golde, 1998; Lovitts, 2001). (p. 49)

Others (e.g., Sternberg \& Williams, 1997; Zwick, 1991) have also found that the GRE and MAT are not good predictors of graduate school success. The over-reliance on these tests is disappointing, mainly because faculty want intelligent students and would like to believe that the more intelligent students produce more creative dissertations. Unfortunately, currently there is no research in this area. There is a need to increase the research on intelligence in relation to doctoral students in order to understand the role of intelligence in becoming a skilled and knowledgeable researcher.

\section{Individual Resources: Motivation}

There is very little research on doctoral student motivation (Wellington \& Sikes, 2006). Jablonski (2001) identified six reasons for students to be motivated to begin a doctoral program. These included the following: (a) the desire to realize a dream, (b) the desire to create an organizing framework for professional development, (c) the desire to change careers, (d) current career demands, (e) the program was located nearby, and (f) the type of program available.

Scott, Brown, Lunt, and Thorne (2004) identified extrinsic and intrinsic motivations for doctoral students. Most students who were categorized as having extrinsic motivation were at the start of their careers and needed the degree for their career development. The students who had intrinsic motivation were most likely well established in a career and were getting the degree for the intellectual challenge and personal fulfillment. Recently, Wellington and Sikes (2006) utilized the concept of intrinsic and extrinsic motivation for doctoral students. Their results were contrary to Scott et al.; their results indicated that most students could not be classified as having intrinsic or extrinsic motivation. Thus, the motivation of doctoral students is unclear, especially in relation to what type of motivation is necessary to develop into a skilled and knowledgeable researcher.

\section{Individual Resources: Knowledge}

The major goals in obtaining a Ph.D. are to obtain knowledge in order to produce scholarly work and research (Association of American Universities, 1998). Jablonski (2001) found that most students "saw doctoral studies as a means of integrating knowledge and experience in a comprehensive framework" (p. 221). To successfully obtain a Ph.D., two types of knowledge are necessary: the knowledge to produce research and the knowledge of how to navigate the culture of the department (Delamont, Atkinson \& Parry, 2000). Interestingly, there is little research on departmental culture. Thus, how students are to understand the culture is unknown.

\section{Individual Resources: Personality}

There has not been any research on personality traits of successful doctoral students. There has been research on personality traits of students who complete a dissertation or delay (Green, 1997). Personality traits that are not related to completion or non-completion of a dissertation include psychosocial immaturity (Weiss, 1987), locus of control (Wagner, 1986), alienation (Girves $\&$ Wemmerus, 1988), and achievement via conformance (Hobish, 1978).

Personality traits that have been found to be significantly correlated with non-completion of a dissertation include inability to plan ahead (Sternberg, 1985), lower levels of masculinity (Ho- 
bish, 1978), lower levels of persistence (Weiss, 1987), perfectionism (Germeroth, 1991), and procrastination (Muszynski \& Akamatsu, 1991). Green (1997) surmised that procrastination and perfectionism are related and "that both may be viewed as expression of control stemming from deficits in self-esteem" (p. 58). Green studied students who had graduated and those who were still "all but dissertation" (ABD) and found significant differences between these two groups on their procrastination. Specifically, the students who were ABD presented with significantly lower frustration tolerance, rebellion, difficulty making decisions, unable to receive help, selfdenigration, insufficient reinforcement or lack of structure, and task aversiveness. Thus, it appears students who complete a dissertation have different personality traits than those who do not complete. Yet, it is unknown what type of personality traits are needed to become a skilled and knowledgeable researcher.

\section{Individual Resources: Thinking Styles}

According to Lovitts (2005) thinking styles are how one capitalizes on and directs one's intelligence(s). They are believed to be "a key ingredient in creativity" (Sternberg \& Lubart, 1995, p. 7). In contrast to ability or intelligence, which signify how well a person can do something, thinking styles signify how a person prefers to use the abilities he or she has (Sternberg, 1997; Sternberg \& Lubart, 1995).

In order to perform well at a task, one's thinking style needs to be matched with whatever thinking style is needed for the given task (Sternberg \& Lubart, 1995). Thus, students need to have a thinking style that matches both the coursework and the dissertation stages that are required to obtain a Ph.D.

\section{Synthesizing the Theories}

After reviewing these theories, it is interesting how the frameworks of scientific and technical (S\&T) human capital (Bozeman et al., 2001), Levine (2007), and Lovitts (2005) are interwoven. For example, the literature on the Macroenvironment (i.e., the culture of graduate education and the culture of the discipline) identified how students across universities should be experiencing very similar cultures; graduate students have similar stresses (e.g., incorporating graduate school into family life, issues with paying for school, etc.). According to the theory of S\&T human capital, if the Macroenvironment is similar across universities, then all students would have comparable S\&T human capital. Levine's (2007) study identified the fact that programs are different; therefore, it can be thought that students would not have similar S\&T human capital.

The Microenvironment (i.e., the location, peers/other faculty, and advisor/mentor) extant literature clearly delineated the importance of the advisor/mentor relationship, the reality that many graduate students do not relocate to attend school, and the significance of peer relationships. The Microenvironment concepts connect with the S\&T human capital theory; relationships are significant and increase a researcher's ability to access research to conduct, leading them to become skilled and knowledgeable. Thus, Levine's (2007) identification of exemplary programs of education will assist only those who live close to these schools or are willing to relocate. Furthermore, only schools with budgets that allow faculty time to work with students will have students who are skilled and knowledgeable researchers.

The literature on Programs (i.e., curriculum, instruction, assessment, and standards) outlines the significance of the program in relation to producing successful researchers. Yet again, the S\&T human capital theory drives this layer. The more human capital a researcher obtains, the more successful the researcher can become. Also, Levine's (2007) work is interwoven throughout this literature. 
Finally, the literature on Individual Resources (i.e., intelligence, knowledge, motivation, thinking styles, and personality) brought to the fore the importance-of students' personal characteristics and the lack of research in this area. This last layer fits with the theory of S\&T human capital, as individual resources are just one aspect of a researcher's human capital. Interestingly, Levine's (2007) study focuses on the program and does not address individual factors. Thus, one is left to wonder how the individual factors interact with the program; if a highly intelligent, motivated, and knowledgeable student attends a school that does not meet all nine areas in Levine's study, does that mean the student cannot become a successful researcher? This phenomenon needs to be examined in order to understand the relationship between individual resources and program.

\section{A New Model for Understanding Skilled and Knowledgeable Researchers}

After reviewing the extant literature regarding developing skilled and knowledgeable researchers, it is evident that the existing theories/studies of Bozeman, Dietz, \& Gaughan, (2001), Levine (2007), and Lovitts (2005) are not complete. It is apparent that there are multiple areas of importance when considering the development of skilled and knowledgeable researchers including human capital (e.g., knowledge and personality type), program features, and the culture of education. Thus, to incorporate all these factors, a new model has been developed.

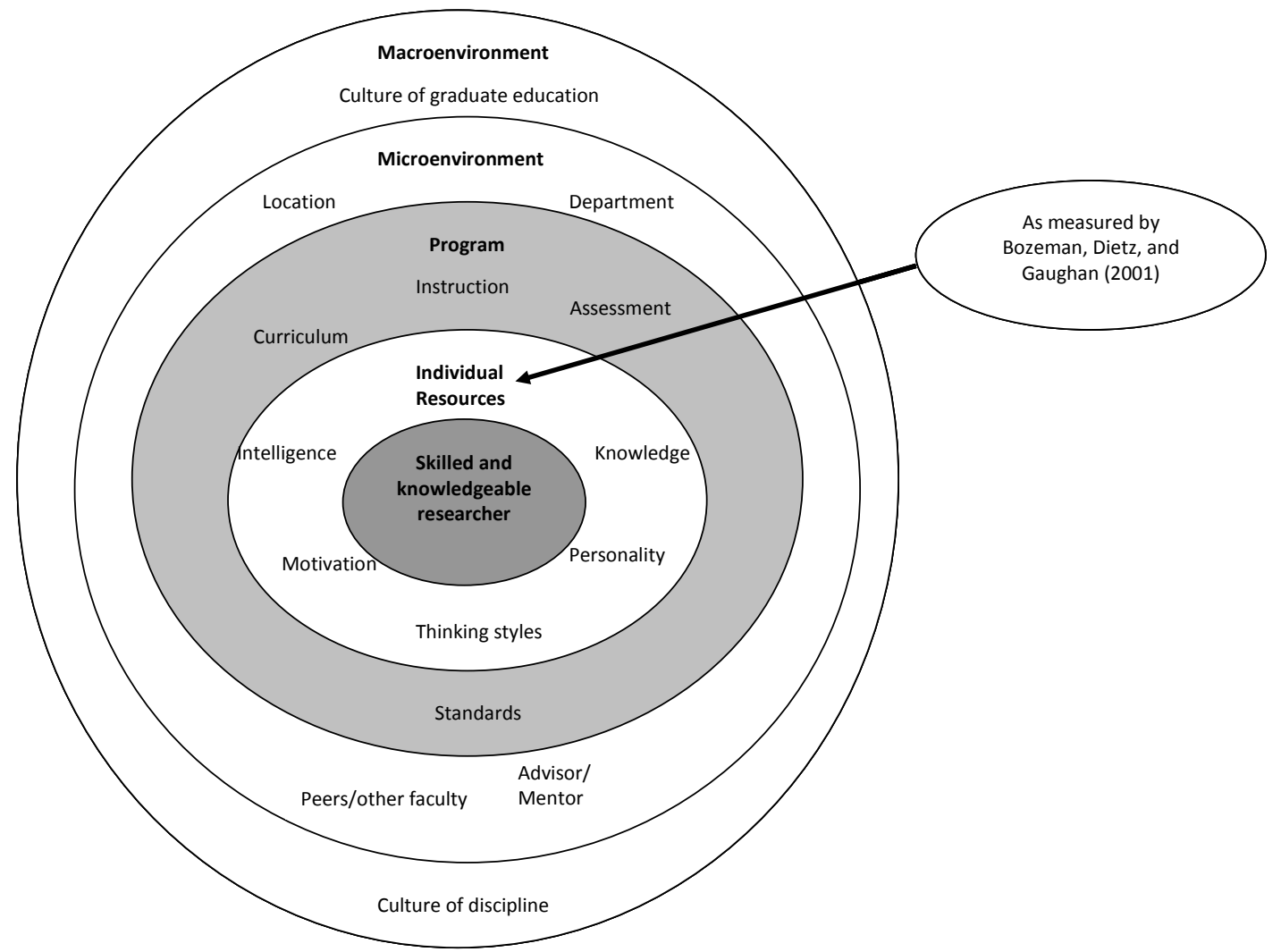

Figure 5. New model for developing skilled and knowledgeable researchers.

Building on Lovitts' (2005) model, by integrating Levine's (2007) and Bozeman, Dietz, \& Gaughan's (2001) concepts as well as the extant literature on skilled and knowledgeable researchers, a new model for understanding how to develop skilled and knowledgeable researchers is presented in Figure 5. Lovitts' model has been modified by replacing the core of doctoral student completion and creative performance with "skilled and knowledgeable researchers." Fur- 
thermore, one layer and several components have been added. Drawing from Bozeman, Dietz, \& Gaughan, individual resources are measured by human and social capital. Finally, based on Levine's study, a fourth layer of "Program" has been added with the following components derived from Levine as well as other extant literature: curriculum, instruction, assessment, courses, standards, qualifying exam, and dissertation.

\section{Conclusion}

The purpose of this paper was to present three theories/studies, review the extant literature, and delineate a new model to assist faculty in thinking about educating skilled and knowledgeable researchers in schools of education. The three theories/studies by Bozeman, Dietz, \& Gaughan, (2001), Levine (2007), and Lovitts (2005) provided a foundation for understanding recent thoughts about educating skilled and knowledgeable researchers. Reviewing the extant literature provided an in-depth look at the concerns regarding educating skilled and knowledgeable researchers. Finally, the new model synthesized the three theories/studies and the extant literature to create an inclusive view of the components needed to educate skilled and knowledgeable researchers.

It is hoped that this model provides a more comprehensive framework than past models, theories, and studies. The new model hopefully will help faculty in schools of education better understand how to educate students to produce knowledgeable and skilled researchers. For example, this understanding may impact the way in which experiences in a doctoral program are conceived, such as course work and research experiences. Furthermore, with increased understanding of these concepts, faculty will be assisted with obtaining deeper understandings of student characteristics (e.g., how to nurture personal characteristics) and how to work with these characteristics to grad-

uate successful researchers (Walker, et al., 2008). As Walker et al. (2008) state, "Serious thinking about what works in doctoral education, and what no longer works, is an urgent matter" (p. 5). It is unfortunately true that "a serious discussion of how to prepare scholars in research methodology is relatively uncharted" (Tashakkori \& Creswell, 2009, p. 291). Therefore, it is hoped that this new model provides a start to charting our way for educating skilled and knowledgeable researchers in schools of education.

\section{References}

American Educational Research Association. (2006). Standards for reporting on empirical social science research in AERA publications. Educational Researcher, 35(6), 33-40.

Anderson, L. E., \& Carta-Falsa, J. (2002). Factors that make faculty and student relationships effective. College Teaching, 50(4), 134-139. doi:10.1080/87567550209595894

Anderson, E. M., \& Shannon, A. L. (1988). Toward a conceptualization of mentoring. Journal of Teach Education, 39, 38-42. doi:10.1177/002248718803900109

Association of American Universities. (1998). Committee on graduate education report and recommendations. Washington, DC: Author.

Bargar, R. R., \& Mayo-Chamberlain, J. (1983). Advisor and advisee issues in doctoral education. The Journal of Higher Education, 54(4), 407-432. doi:10.2307/1981905

Bourdieu, P., \& Wacquant, L. J. D. (1992). An invitation to reflexive sociology. Chicago, IL: University of Chicago Press.

Bowen, W. G., \& Rudenstine, N. L. (1992). In pursuit of the Ph.D. Princeton, NJ: Princeton University Press. 
Bozeman, B., Dietz, J. S., \& Gaughan, M. (2001). Scientific and technical human capital: An alternative model for research evaluation. International Journal of Technology Management, 22(7-8), 716-740. doi:10.1504/IJTM.2001.002988

Delamont, S., Atkinson, P., \& Parry, O. (2000). The doctoral experience: Success and failure in graduate school. London, England: Falmer Press.

Elmore, P. B., Lewis, E. L., \& Bay, M. L. G. (1993, April). Statistics achievement: A function of attitudes and related experience. Paper presented at the annual meeting of the American Educational Research Association. (ERIC Document Reproduction Service No. 360324)

Endsley, R. C., \& Giles, H. W. (1988). Assessing career development relationship in academe. Career Planning and Adult Development Journal, 4, 22-28.

Feuer, M. J., Towne, L., \& Shavelson, R. J. (2002). Scientific culture and educational research. Educational Researcher, 31, 4-14. doi:10.3102/0013189X031008004

Fitzgerald, S. M., Jurs, S., \& Hudson, L. M. (1996). A model predicting statistics achievement among graduate students. College Student Journal, 30, 361-366.

Gardner, H. (1983). Frames of mind: The theory of multiple intelligences. New York, NY: Basic Books.

Germeroth, D. (1991). Lonely days and lonely nights: Completing the doctoral dissertation. ACA Bulletin, $76,60-89$.

Giles, H. W., \& Endsley, R. C. (1988). Early career development among child and family development professionals: The role of professor and peer relationships. Family Relations, 37, 470-476. doi: $10.2307 / 584122$

Girves, J. E., \& Wemmerus, V. (1988). Developing models of graduate student degree progress. Journal of Higher Education, 59(2), 163-189. doi:10.2307/1981691

Golde, C. M. (2005). The role of the department and discipline in doctoral student attrition: Lessons from four departments. The Journal of Higher Education, 76(6), 669-700. doi:10.1353/jhe.2005.0039

Golde, C. M., \& Dore, T. M. (2001). At cross purposes: What the experiences of doctoral students reveal about doctoral education (www.Ph.D.-survey.org). Philadelphia, PA: A report prepared for The Pew Charitable Trusts.

Green, K. E. (1997). Psychosocial factors affecting dissertation completion. New Directions for Higher Education, 99, 57-65. doi:10.1002/he.9905

Hobish, T. T. (1978). A study of selected psychological factors related to completion or non-completion of the doctoral dissertation among male and female doctoral candidates. (Doctoral Dissertation, New York University, 1978). Dissertation Abstracts International, 39(04), 1934-B.

Hostetler, K. (2005). What is "good" educational research? Educational Researcher, 34, 16-21.

Jablonski, A. M. (2001). Doctoral studies as professional development of educators in the United States. European Journal of Teacher Education, 24(2), 215-222. doi:10.1080/02619760120095606

Jiranek, V. (2010). Potential predictors of timely completion among dissertation research students at an Australian faculty of sciences. International Journal of Doctoral Studies, 5, 1-13. Retrieved from http://ijds.org/Volume5/IJDSv5p001-013Jiranek273.pdf

Johnson, R. B., \& Onwuegbuzie, A. J. (2004). Mixed methods research: A research paradigm whose time has come. Educational Researcher, 33, 13-26.

Kram, K., \& Isabella, L. (1985). Mentoring alternatives: The role of peer relationships in career development. Academy of Management Journal, 28, 110-132. doi:10.2307/256064

Lagemann, E., \& Shulman, L. (Eds.). (1999). Issues in education research: Problems and possibilities. San Francisco, CA: Jossey-Bass. 
Lalonde, R. N., \& Gardner, R. C. (1993). Statistics as a second language? A model for predicting performance in psychology students. Canadian Journal of Behavioral Science, 25, 108-125.

Leech, N. L., \& Goodwin, L. D. (2008). Building a methodological foundation: Doctoral-level methods courses in colleges of education. Research in the Schools, 15, 1-8.

Levine, A. (2007). Educating researchers. Washington, DC: The Education Schools Project.

Lovitts, B. E. (2001). Leaving the ivory tower: The causes and consequences of departure from doctoral study. Lanham, MD: Rowman \& Littlefield.

Lovitts, B. E. (2005). Being a good course-taker is not enough: A theoretical perspective on the transition to independent research. Studies in Higher Education, 30(2), 137-154. doi:10.1080/03075070500043093

Luna, G., \& Cullen, D. (1998). Do graduate students need mentoring? College Students Journal, 33(3), 322-330.

McAlpine, L., \& Norton, J. (2006). Reframing our approach to doctoral programs: An integrative framework for action and research. Higher Education Research \& Development, 25, 3-17. doi:10.1080/07294360500453012

Mundfrom, D. J., Shaw, D. G., Thomas, A., Young, S., \& Moore, A. D. (2003). Introductory graduate research courses: An examination of the knowledge base. Research in the Schools, 10(2), 71-78.

Mupinga, E. E., \& Mupinga, D. M. (2005). Perceptions of international students toward GRE. College Student Journal, 39(7), 402-408.

Murtonen, M., \& Lehtinen, E. (2003). Difficulties experienced by education and sociology students in quantitative methods courses. Studies in Higher Education, 28, 171-185. doi:10.1080/0307507032000058064

Muszynski, S. Y., \& Akamatsu, T. J. (1991). Delay in completion of doctoral dissertation in clinical psychology. Professional Psychology: Research and Practice, 22, 119-123.

National Research Council. (1996). The path to the Ph.D.: Measuring graduate attrition in the sciences and humanities. Washington, DC: National Academy Press.

National Research Council. (2002). Scientific research in education. In R. J. Shavelson \& L. Towne (Eds.), Committee on scientific principles for educational research. Washington, DC: National Academy Press.

Nerad, M., \& Cerny, J. (1991). From facts to action: Expanding the educational role of the graduate division. Washington, DC: Council of Graduate Study.

Onwuegbuzie, A. J. (1997). Writing a research proposal: The role of library anxiety, statistics anxiety, and composition anxiety. Library \& Information Science Research, 19, 5-33. doi:10.1016/S07408188(97)90003-7

Onwuegbuzie, A. J. (2000, November). On becoming a bi-researcher: The importance of combining quantitative and qualitative research methodologies. Paper presented at the annual meeting of the Association for the Advancement of Educational Research (AAER), Ponte Vedra, FL.

Onwuegbuzie, A. J., \& Leech, N. L. (2005a). On becoming a pragmatic researcher: The importance of combining quantitative and qualitative research methodologies. International Journal of Social Research Methodology: Theory and Practice, 8(5), 375-387. doi:10.1080/13645570500402447

Onwuegbuzie, A. J., \& Leech, N. L. (2005b). Taking the "Q" out of research: Teaching research methodology courses without the divide between quantitative and qualitative paradigms. Quality and Quantity: International Journal of Methodology, 39, 267-296. doi:10.1007/s11135-004-1670-0

Onwuegbuzie, A. J., \& Seaman, M. (1995). The effect of time and anxiety on statistics achievement. Journal of Experimental Psychology, 63, 115-124. doi:10.1080/00220973.1995.9943816 


\section{Educating Knowledgeable and Skilled Researchers}

Onwuegbuzie, A. J., Slate, J., Paterson, F., Watson, M., \& Schwartz, R. (2000). Factors associated with underachievement in educational research courses. Research in the Schools, 7, 53-65.

Onwuegbuzie, A. J., \& Wilson, V. A. (2003). Statistics anxiety: Nature, etiology, antecedents, effects, and treatments: A comprehensive review of the literature. Teaching in Higher Education, 8, 195-209.

Page, R. N. (2001). Reshaping graduate preparation in educational research methods: One school's experience. Educational Researcher, 30(5), 19-25. doi:10.3102/0013189X030005019

Paglis, L. L., Green, S. G., \& Bauer, T. N. (2006). Does adviser mentoring add value? A longitudinal study of mentoring and doctoral student outcomes. Research in Higher Education, 47(4), 451-476. doi:10.1007/s11162-005-9003-2

Pierce, T. B., \& Smith, D. D. (1994). Career choices of recent special education graduates holding doctoral degrees. Teacher Education and Special Education, 17(2), 129-136. doi:10.1177/088840649401700207

Pinar, W. F. (2004). What is curriculum theory? Mahwah, NJ: Lawrence Erlbaum.

Pinar, W. F., Reynolds, W. M., Slattery, P., \& Taubman, P. M. (1995). Understanding curriculum: An introduction to historical and contemporary curriculum discourse. New York, NY: Peter Lang.

Pontius, J. L., \& Harper, S. R. (2006). Principles for good practice in graduate and professional student engagement. New Directions for Student Services, 115, 47-58. doi:10.1002/ss.215

Posner, G. J. (1992). Analyzing the curriculum. New York, NY: McGraw-Hill.

Rose, G. L. (2003). Enhancement of mentor selection using the ideal mentor scale. Research in Higher Education, 44(4), 473-494.

Samuel, R. E., \& Kohun, F. G. (2010). Managing perceived coping behavior while mentoring doctoral students. International Journal of Doctoral Studies, 5, 29-37. Retrieved from http://ijds.org/Volume5/IJDSv5p029-037Samue291.pdf

Saroyan, A., Amundsen, C., McAlpine, L., Weston, C., Winer, L., \& Gandell, T. (2004). Tenets underlying our approach to faculty development. In A. Saroyan \& C. Amundsen (Eds.), Rethinking teaching in higher education: From a course design workshop to a faculty development framework (pp. 15-29). Sterling, VA: Stylus.

Scott, D., Brown, A., Lunt, I., \& Thorne, L. (2004). Professional doctorates: Integrating professional and academic knowledge. Maidenhead, UK: Open University Press.

Sternberg, R. J. (1985). Beyond IQ: A triarchic theory of human intelligence. New York: Cambridge University Press.

Sternberg, R. J. (1997). Successful intelligence: How practice and creative intelligence determine success in life. New York, NY: Plume.

Sternberg, R. J., \& Lubart, T. I. (1995). Defying the crowd: Cultivating creativity in a culture of conformity. New York, NY: Free Press.

Sternberg, R. J., \& Williams, W. (1997). Does the graduate record examination predict meaning success in the graduate training of psychologists? A case study. American Psychologist, 52(6), 630-641. doi:10.1037//0003-066X.52.6.630

Tashakkori, A., \& Creswell, (2009). Envisioning the future stewards of the social-behavioral research enterprise. Journal of Mixed Methods Research, 2, 291-295.

Tashakkori, A., \& Teddlie, C. (2003). Issues and dilemmas in teaching research methods courses in social and behavioral sciences: A US perspective. International Journal of Social Research Methodology, 6(1), 61 - 77. doi:10.1080/13645570305055

Tyler, N. C., \& Smith, D. D. (1999). Career decisions of doctoral graduates in special education. Teacher Education and Special Education, 21(3), 1-13. 
Tyler, N. C., Smith, D. D., \& Pion, G. M. (2003). Doctoral students in special education: Characteristics and career aspirations. Teacher Education and Special Education, 26(3), 194-205. doi:10.1177/088840640302600306

Wagner, D. V. (1986). Selected personality characteristics and situational factors as correlates of completion and non-completion of the doctoral dissertation (Doctoral dissertation, University of Michigan, 1986). Dissertation Abstracts International, 47, 3377A.

Walker, G. E., Golde, C. M., Jones, L., Conklin Bueschel, A., \& Hutchings, P. (2008). The formation of scholars: Rethinking doctoral education for the twenty-first century. San Francisco, CA: Jossey-Bass.

Weiss, L. D. (1987). The relationship between personality variables and the completion of a doctoral dissertation. Dissertation Abstracts International, 48 (09), 2814B. (University Microfilms No. AAG8720990)

Wellington, J., \& Sikes, P. (2006). 'A doctorate in a tight compartment': Why do students choose a professional doctorate and what impact does it have on their personal and professional lives? Studies in Higher Education, 31(6), 723-734. doi:10.1080/03075070601004358

Zanakis, S. H., \& Valenza, E. R. (1997). Student anxiety and attitudes in business statistics. Journal of Education for Business, 72(5), 10-16. doi:10.1080/08832329709601608

Zeidner, M. (1990). Does test anxiety bias scholastic aptitude test performance by gender and sociocultural group? Journal of Genetical Psychology, 150, 175-185. doi:10.1207/s15327752jpa5501\&2_14

Zeidner, M. (1991). Statistics and mathematics anxiety in social science students - Some interesting parallels. British Journal of Educational Psychology, 61, 319-328.

Zwick, R. (1991). Differences in graduate school attainment patterns across academic programs and demographic groups. Princeton, NJ: Educational Testing Service.

\section{Biography}

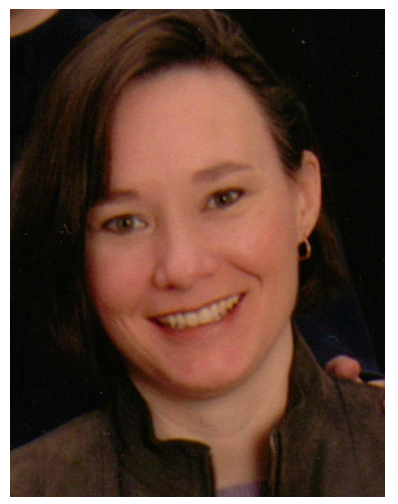

Nancy L. Leech, Ph.D. is an associate professor at the University of Colorado Denver. Dr. Leech is currently teaching master's and Ph.D. level courses in research, statistics, and measurement. Her area of research is promoting new developments and better understandings in applied qualitative, quantitative, and mixed methodologies. To date, she has published more than 60 articles in refereed journals, and is coauthor of three books; SPSS for Basic Statistics: Use and Interpretation, SPSS for Intermediate Statistics: Use and Interpretation, and Research Methods in Applied Settings: An Integrated Approach to Design and Analysis, all published by Taylor and Francis. Dr. Leech has made more than 70 presentations at regional, national, and international conferences. 